Biochimica et Biophysica Acta, 481 (1977) 212-221

(C) Elsevier/North-Holland Biomedical Press

BBA 68057

\title{
SULFHYDRYL GROUPS IN RELATION TO THE STRUCTURE AND CATALYTIC ACTIVITY OF 2-OXO-4-HYDROXYGLUTARATE ALDOLASE FROM BOVINE LIVER
}

\author{
ROGER S. LANE *, BARBARA A. HANSEN ** and EUGENE E. DEKKER *** \\ Department of Biological Chemistry, The University of Michigan, Ann Arbor, Mich. 48109 \\ (U.S.A.)
}

(Received October 12th, 1976)

\section{Summary}

Bovine liver 2-oxo-4-hydroxyglutarate aldolase (suggested name: 2-oxo-4hydroxyglutarate glyoxylate-lyase catalyzing the reaction: 2-oxo-4-hydroxyglutarate $\rightleftharpoons$ pyruvate + glyoxylate) contains eight to ten sulfhydryl groups as determined by titration of the enzyme with either 5,5'-dithiobis(2-nitrobenzoic acid) $\left(\mathrm{Nbs}_{2}\right)$ or $p$-mercuribenzoate in the presence of $1 \%$ sodium dodecyl sulfate. In the absence of a denaturant, all of the cysteinyl residues react with $p$-mercuribenzoate whereas only four are accessible to titration with $\mathrm{Nbs}_{2}$. No differences in -SH group reactivity can be detected during titration of the aldolase with $p$-mercuribenzoate. In contrast, two classes of sulfhydryls can be differentiated in the disulfide exchange reaction with $\mathrm{Nbs}_{2}$ in the absence of a denaturant; one -SH group (Class I) reacts rapidly whereas three additional thiols (Class II) titrate at approx. 0.1 the rate of the Class I -SH residue. Both pyruvate and glyoxylate protect one of the three -SH residues in Class II from reaction with $\mathrm{Nbs}_{2}$. Either substrate also prevents titration of one to two thiol groups by $p$-mercuribenzoate and decreases the rate of reaction of aldolase -SH groups with $\mathrm{Nbs}_{2}$ in $8 \mathrm{M}$ urea. These ligand-induced changes in - $\mathrm{SH}$ reactivity provide a sensitive indication that the enzyme exists in an altered conformational state in the presence of either of its cosubstrates.

Titration of the enzyme with either $\mathrm{Nbs}_{2}$ or $p$-mercuribenzoate results in a progressive loss of aldolase activity which is not proportional to the number of -SH groups modified. The enzyme retains $50 \%$ of the activity of the native enzyme when Class I and Class II thiols (i.e. four -SH groups total) are modified

* Present address: Department of Biochemistry, State University of New York at Buffalo, Buffalo, N.Y. 14214, U.S.A.

** Present address: Department of Immunology, Rush Medical School, Chicago, Ill. 60612, U.S.A.

*** To whom correspondence should be addressed. Abbreviation: $\mathrm{Nbs}_{2}, 5.5$-dithiobis(2-nitrobenzoic acid). 
with $\mathrm{Nbs}_{2} ; 15 \%$ residual activity is still observed following titration of all of the cysteinyl residues with $p$-mercuribenzoate. Pyruvate and glyoxylate provide partial protection against inactivation. It is concluded that inactivation of 2-oxo-4-hydroxyglutarate aldolase by $\mathrm{Nbs}_{2}$ or $p$-mercuribenzoate is a consequence of alterations in protein structure which accompany modification of -SH groups. The data argue against the direct participation of an active-site thiol group in the catalytic mechanism of 2-oxo-4-hydroxyglutarate aldolase, be that aldol cleavage and condensation or $\beta$-decarboxylation.

\section{Introduction}

2-Oxo-4-hydroxyglutarate aldolase from bovine liver, an important enzyme in L-hydroxyproline catabolism, catalyzes the reversible dealdolization of 2-oxo-4-hydroxyglutarate yielding pyruvate and glyoxylate. The enzyme also exhibits appreciable $\beta$-decarboxylase activity toward oxalacetate, catalyzing the formation of pyruvate and carbon dioxide at about one-half the rate of 2-oxo4-hydroxyglutarate cleavage $[1,2]$. Both reactions proceed by Schiff-base mechanisms involving the $\epsilon$-amino group of an active-site lysyl residue; this has been shown by (a) demonstrating the irreversible loss of catalytic activity and stable incorporation of isotope following reduction of the enzyme with $\mathrm{NaBH}_{4}$ in the presence of ${ }^{14} \mathrm{C}$-labeled substrates and/or products [3,4] and (b) isolating the predicted secondary amine from acid hydrolysates of the borohydridereduced pyruvate aldolase ketimine complex [4]. Similar experiments using either $\mathrm{BH}_{4}^{-}$or $\mathrm{CN}^{-}$as a trapping agent [3-5] indicated that glyoxylate also forms an azomethine with the active-site region of 2-oxo-4-hydroxyglutarate aldolase, an interaction which is mutually exclusive with imine formation with either pyruvate or 2-oxo-4-hydroxyglutarate.

Earlier work [6] showed that 2-oxo-4-hydroxyglutarate aldolase activity is sensitive to inhibitors normally assumed to react with protein sulfhydryl groups, including $p$-mercuribenzoate, $N$-ethylmaleimide, and iodoacetate. More recently, it was demonstrated that both the aldolase and $\beta$-decarboxylase activities of the enzyme are abolished when four thiol residues are oxidized with tetranitromethane [7]. The studies reported here were undertaken to determine the number of sulfhydryl groups in bovine liver 2-oxo-4-hydroxyglutarate aldolase, to examine the reactivity of these groups in the absence and presence of substrates, and to investigate more fully the relationship of sulfhydryl groups to the catalytic activities of this aldolase.

\section{Materials and Methods}

\section{Materials}

2-Oxo-4-hydroxyglutarate aldolase was purified from extracts of bovine liver [6]; final preparations of the enzyme were determined to be homogeneous by polyacrylamide gel electrophoresis at $\mathrm{pH}$ 9.3. The aldolase used in these studies had a specific activity of 150-180 ( $\mu \mathrm{mol}$ glyoxylate formed/20 min per $\mathrm{mg}$ protein at $37^{\circ} \mathrm{C}$ ) and, before being used, was dialyzed overnight at $4^{\circ} \mathrm{C}$ against the appropriate buffer. 
DL-2-Oxo-4-hydroxyglutarate was prepared by non-enzymic transamination of threo- $\gamma$-hydroxy-DL-glutamate [8]. $\mathrm{Nbs}_{2}$ was purchased from Aldrich (Milwaukee, U.S.A.) and recrystallized twice from glacial acetic acid. $p$-Mercuribenzoate was obtained from Sigma (St. Louis, U.S.A.). Solutions of $p$-mercuribenzoate were prepared by dissolving $10 \mathrm{mg}$ of the sodium salt in $4 \mathrm{ml}$ of $0.01 \mathrm{M}$ $\mathrm{NaOH}$ followed by dilution to a volume of $25 \mathrm{ml}$ with $10 \mathrm{mM}$ potassium phosphate buffer ( $\mathrm{pH} 7.0$ ). Such solutions were stable for at least 2 weeks when stored in the dark at room temperature. The concentration of each solution was determined spectrophotometrically at $232 \mathrm{~nm}$ using a molar extinction coefficient of $1.69 \cdot 10^{4} \mathrm{M}^{-1} \cdot \mathrm{cm}^{-1}$ [9] and verified by titrating a primary reference solution of reduced glutathione. Sodium pyruvate, sodium glyoxylate and oxalacetate were obtained from Nutritional Biochemicals (Cleveland, U.S.A.), and "ultra pure" sodium dodecyl sulfate from Sigma (St. Louis, U.S.A.). Solutions of urea were freshly prepared from material which had been recrystallized twice from $70 \%$ ethanol, washed with cold ether, and then dried for $24 \mathrm{~h}$ at $60^{\circ} \mathrm{C}$.

\section{Methods}

The concentration of purified 2-oxo-4-hydroxyglutarate aldolase was determined by the method of Lowry et al. [10] or by a modified biuret procedure [11] with crystalline bovine serum albumin as a standard. Molar concentrations of the enzyme were calculated on the basis of a molecular weight of 120000 [6].

2-Oxo-4-hydroxyglutarate aldolase activity was determined by the colorimetric assay of Maitra and Dekker [12]. Oxalacetate $\beta$-decarboxylase activity was monitored spectrophotometrically at $340 \mathrm{~nm}$ by coupling pyruvate formation with excess NADH and lactate dehydrogenase [7].

Titration of 2-oxo-4-hydroxyglutarate aldolase with $\mathrm{Nbs}_{2}$ was performed at $25^{\circ} \mathrm{C}$ in $50 \mathrm{mM}$ Tris $\mathrm{HCl}$ buffer $(\mathrm{pH} \mathrm{8.0)}$ in a final reaction volume of 1.0 ml. Potassium glycylglycine buffer $(\mathrm{pH}$ 8.0) was substituted for Tris in certain instances as specified. The reaction was initiated by the addition of $0.05 \mathrm{ml}$ of a $10 \mathrm{mM}$ solution of $\mathrm{Nbs}_{2}$ in $0.1 \mathrm{M}$ potassium phosphate buffer ( $\mathrm{pH} \mathrm{7.0)}$ to $0.95 \mathrm{ml}$ of a solution of the aldolase $(0.3-0.9 \mathrm{mg} / \mathrm{ml})$; the rate of reaction was monitored by following the change in absorbance at $412 \mathrm{~nm}$ with time using a Gilford spectrophotometer equipped with a thermostatted cell compartment and a digital readout meter. A molar extinction coefficient of $13600 \mathrm{M}^{-1}$. $\mathrm{cm}^{-1}$ was used to calculate the number of sulfhydryl groups titrated [13].

The kinetics of $\mathrm{Nbs}_{2}$ titrations were analyzed by pseudo first-order plots of $\log (a-x)$ versus time where $a$ is the $-\mathrm{SH}$ titer after completion of the reaction and $x$ is the number of thiols titrated at a given time, $t$. With biphasic plots (see Fig. 1A), values for the apparent first-order rate constant $\left(k_{\text {obs }}\right)$ of sulfhydryl residues with different reactivities and the number of residues in each category were determined as described by Frost and Pearson [14].

2-Oxo-4-hydroxyglutarate aldolase was titrated spectrophotometrically with $p$-mercuribenzoate as described by Boyer [9] and further elaborated by Benesch and Benesch [15]. Titration of the enzyme $(0.45-0.50 \mathrm{mg} / \mathrm{ml})$ was carried out in $10 \mathrm{mM}$ Tris $\cdot \mathrm{HCl}$ buffer ( $\mathrm{pH} 7.4)$ at $26^{\circ} \mathrm{C}$ by sequential addition of $5 \mu \mathrm{l}$ aliquots of $p$-mercuribenzoate (approx. $1 \mathrm{mM}$ ). The increase in absor- 
bance at $250 \mathrm{~nm}$ was measured after each addition and plotted against the amount of $p$-mercuribenzoate added [9]. Aliquots of $p$-mercuribenzoate were usually added 15-20 $\mu$ l past the equivalence point.

\section{Results}

Number and reactivity of thiol groups of bovine liver 2-oxo-4-hydroxyglutarate aldolase

The number of sulfhydryl groups present in 2-oxo-4-hydroxyglutarate aldolase was determined under various conditions; the results are shown in Table I. In the native enzyme, 8-10 -SH residues per 120000 daltons of protein are titrated with $p$-mercuribenzoate. The reaction is complete within a few minutes after each addition of $p$-mercuribenzoate and no differences in the rate of reaction of these thiol groups can be detected during sequential addition of the reagent. The total number of residues titrated with $p$-mercuribenzoate is not increased significantly when the reaction is carried out in $1 \%$ sodium dodecyl sulfate. It appears, therefore, that even in the absence of a denaturant all of the -SH groups in the molecule are readily accessible to $p$-mercuribenzoate.

Reaction of 2-oxo-4-hydroxyglutarate aldolase with $\mathrm{Nbs}_{2}$ in $1 \%$ sodium dodecyl sulfate solution also reveals a total of 8-10 sulfhydryl groups in the protein molecule. Under these conditions, the titration is complete in 20-30 min. If $6 \mathrm{M}$ guanidine $\cdot \mathrm{HCl}$ is used in place of sodium dodecyl sulfate, $\mathrm{Nbs}_{2}$ reacts instantaneously with all of the thiol groups. In the absence of a denaturant, however, only four cysteinyl residues are titrated with $\mathrm{Nbs}_{2}$. In this case, the reaction is complete in 120-180 min and no significant increase in the sulfhydryl titer is observed beyond this time; prolonged incubation $(6 \mathrm{~h})$ of the enzyme with $\mathrm{Nbs}_{2}$ results in the development of turbidity in the reaction mixture. A pseudo first-order plot of the rate of reaction with excess $\mathrm{Nbs}_{2}$ is biphasic (Fig. 1A) indicating the presence of two distinct classes of -SH groups

\section{TABLE I}

TITRATION OF THE SULFHYDRYL GROUPS OF BOVINE LIVER 2-OXO-4-HYDROXYGLU. TARATE ALDOLASE

Titrations of the enzyme with $\mathrm{Nbs}_{2}$ and $p$-mercuribenzoate were carried out as described in the section entitled Methods. Each number listed represents the average value of several determinations with a number of different preparations of the aldolase.

\section{$\mathrm{Nbs}_{2}$}

$\mathrm{Nbs}_{2}$ in $1 \%$ sodium dodecyl sulfate

p-Mercuribenzoate

p-Mercuribenzoate in $1 \%$ sodium

dodecyl sulfate

\author{
$4.07 \pm 0.15 * *$ \\ $8.20 \pm 0.05$ \\ $10.15 \pm 0.05$ \\ $10.00 \pm 0.20$
}

For reasons not yet established, different preparations of the adolase show a total of either eight or ten -SH groups. Hence the variation in the values listed. If, however, a given sample showed eight SH groups by titration with $\mathrm{Nbs}_{2}$ in $1 \%$ sodium dodecyl sulfate, a total of eight likewise reacted with $p$-mercuribenzoate (with or without denaturant present). The same was routinely true for preparations having ten titratable -SH groups.

** Average deviation of the mean. 


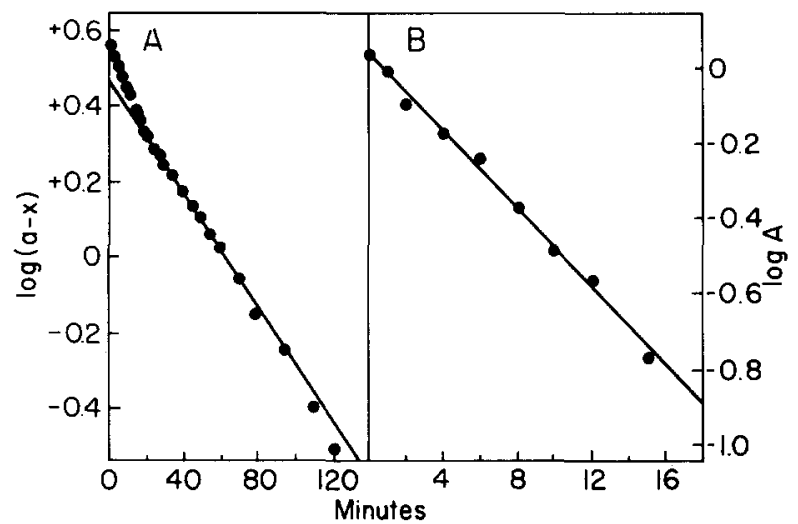

Fig. 1.(A) Pseudo first-ordex plot for the titration of 2-oxo-4-hydroxyglutarate aldolase -SH groups with $\mathrm{Nbs}_{2}$ in the absence of a denaturant. Aldolase $(0.38 \mathrm{mg} / \mathrm{ml})$ was incubated at $25^{\circ} \mathrm{C}$ in $50 \mathrm{mM}$ Tris $\cdot \mathrm{HCl}$ buffer (pH 8.0) containing $0.5 \mathrm{mM} \mathrm{Nbs}_{2}$. The labeling of the ordinate is defined in Methods. (B) Replot of the data obtained in the fast phase of the reaction shown in $A$. The ordinate represents the logarithm of the concentration of the more reactive component corrected for the contribution of the slower reacting -SH groups [14]. The change in scales from A should be noted.

with different reactivities toward $\mathrm{Nbs}_{2}$. The apparent first-order rate constant $\left(k_{\text {obs }}\right)$ for the slow phase of the titration is computed to be $1.7 \cdot 10^{-2} \mathrm{~min}^{-1}$; this class (Class II) was found to consist of three -SH groups. If one corrects the experimental results obtained in the early phase of the reaction for the contribution of the slower reacting $-\mathrm{SH}$ groups (Fig. 1B), the data indicate that $\mathrm{Nbs}_{2}$ reacts with a single more reactive thiol (Class $\mathrm{I}$, rate constant $=12 \cdot 10^{-2}$ $\min ^{-1}$ ).

\section{Reactivity of thiol groups in the presence of substrates}

Pyruvate and glyoxylate, cosubstrates of the 2-oxo-4-hydroxyglutarate aldolase reaction, markedly influence the titration of enzyme -SH groups by $\mathrm{Nbs}_{2}$ in the absence of a denaturing agent. As shown in Table II, one -SH group of Class II is protected from reaction in the presence of either $10 \mathrm{mM}$ pyruvate or $10 \mathrm{mM}$ glyoxylate. Moreover, either one of these cosubstrates diminishes the rate of titration of the Class I thiol as well as of the two remaining Class II

\section{TABLE II}

REACTIVITY OF ALDOLASE SULFHYDRYL GROUPS WITH Nbs, OR $p$-MERCURIBENZOATE IN THE PRESENCE OF SUBSTRATES

Titration of the enzyme $(0.45 \mathrm{mg} / \mathrm{ml})$ with p-mercuribenzoate was carried out in $10 \mathrm{mM}$ Tris $\cdot \mathrm{HCl}$ buffer (pH 7.4) as outlined in Methods. Aldolase $\left(0.33 \mathrm{mg} / \mathrm{ml}\right.$ ) was titrated with $0.5 \mathrm{mM} \mathrm{Nbs} 2$ at $25^{\circ} \mathrm{C}$ in $50 \mathrm{mM}$ potassium glycylglycine buffer (pH 8.0). Substrates were added as indicated.

\begin{tabular}{|c|c|c|c|c|c|}
\hline \multirow[t]{3}{*}{ Additions } & \multicolumn{3}{|c|}{ Number of reactive sulfhydryl groups } & \multirow{2}{*}{\multicolumn{2}{|c|}{$\begin{array}{l}\text { Titration rate constant with } \\
\mathrm{Nbs}_{2}\left(k_{\mathrm{obs}}\right)\left(\mathrm{min}^{-1} \times 10^{2}\right)\end{array}$}} \\
\hline & \multirow[t]{2}{*}{$p$-Mercuribenzoate } & \multicolumn{2}{|c|}{$\mathrm{Nbs}_{2}$ (mol/mol protein) } & & \\
\hline & & Class I & Class II & Class I & Class II \\
\hline None & 10.3 & 1.1 & 2.9 & 19 & 1.6 \\
\hline $10 \mathrm{mM}$ pyruvate & 8.5 & 1.2 & 1.7 & 10 & 1.0 \\
\hline $10 \mathrm{mM}$ gly oxylate & 9.3 & 1.0 & 1.8 & 10 & 1.0 \\
\hline
\end{tabular}




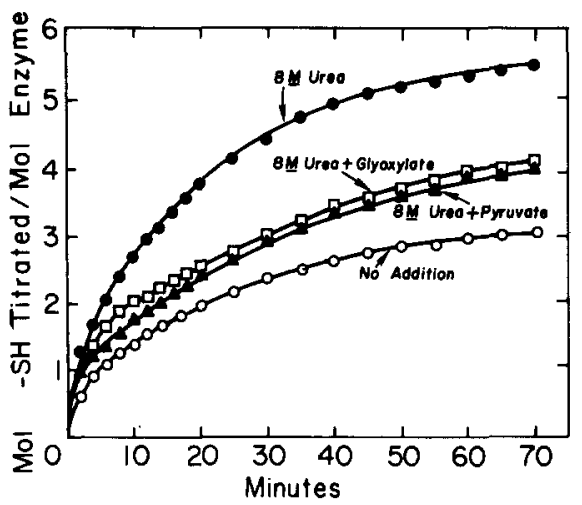

Fig. 2. Effect of substrates on the rate of reaction of thiol groups of 2-oxo-4-hydroxyglutarate aldolase with $\mathrm{Nbs}_{2}$ in the presence of urea. The protein concentration was $0.33 \mathrm{mg} / \mathrm{ml}$; other experimental conditions were the same as in Fig. $1 \mathrm{~A}$. Where indicated, $8 \mathrm{M}$ urea $(\bullet), 8 \mathrm{M}$ urea plus $10 \mathrm{mM}$ pyruvate (4), or 8 $M$ urea plus $10 \mathrm{mM}$ glyoxylate $(\square)$ was added.

cysteinyl residues approx. 2-fold. The effects of pyruvate and glyoxylate are not additive; no additional protection or alteration in titration behavior is observed when both compounds, each at a concentration of $10 \mathrm{mM}$, are present in the same reaction mixture. Added substrates also change the reactivity of 2-oxo-4-hydroxyglutarate aldolase -SH groups with $\mathrm{Nbs}_{2}$ in the presence of a denaturant; the rate of reaction in $8 \mathrm{M}$ urea is diminished considerably in the presence of $10 \mathrm{mM}$ pyruvate or $10 \mathrm{mM}$ glyoxylate (Fig. 2). Again, no additive effects are observed if both ligands $(10 \mathrm{mM}$ each) are present simultaneously during the titration.

A similar protective influence of substrates against sulfhydryl group modification occurs when the native enzyme is titrated with $p$-mercuribenzoate. Although the rates of reaction of the thiol groups with $p$-mercuribenzoate are essentially the same in the presence or absence of either cosubstrate, glyoxylate in this case also protects one -SH group and pyruvate about 1-2 from reacting (Table II). Experiments with numerous preparations of the aldolase showed that either substrate protects 1-2 sulfhydryl groups from being titrated by $p$-mercuribenzoate.

Inhibition of 2-oxo-4-hydroxyglutarate aldolase activity by $\mathrm{Nbs}_{2}$ or p-mercuribenzoate and reactivation by 2-mercaptoethanol

Fig. 3 illustrates the loss of 2-oxo-4-hydroxyglutarate aldolase activity which accompanies titration of aldolase -SH groups by $\mathrm{Nbs}_{2}$ or $p$-mercuribenzoate. One -SH group may be titrated with $\mathrm{Nbs}_{2}$ and at least two with $p$-mercuribenzoate before the enzyme undergoes any significant loss of catalytic activity. Although further modification with either reagent results in a progressive decline in activity, in both cases the observed loss of enzymic activity does not correlate with the number of thiol groups modified. In addition, only $50 \%$ inactivation of enzyme activity is observed when the Class I and Class II cysteinyl residues are titrated with $\mathrm{Nbs}_{2}$, and $15 \%$ residual activity still persists after $p$-mercuribenzoate reacts with all -SH groups in the protein molecule (a total of eight sulfhydryls were titratable in this experiment). Incubation of the 


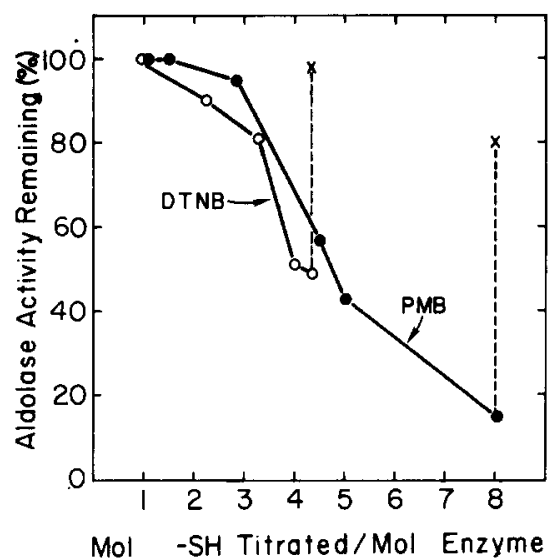

Fig. 3. Extent of inactivation of 2-oxo-4-hydroxyglutarate aldolase by $\mathrm{Nb}_{2}$ or $\mathrm{p}$-mercuribenzoate as a function of sulfhydryl group modification; reactivation by 2 -mercaptoethanol. Aldolase $(0.33 \mathrm{mg} / \mathrm{ml}) \mathrm{was}$ titrated with $\mathrm{Nbs}_{2}$ under the conditions specified in the legend of Fig. $1 \mathrm{~A}$. Aliquots were removed at set time intervals and assayed for aldolase activity. The number of sulfhydryl groups modified was determined from the absorbance change at $412 \mathrm{~nm}$. Aldolase $(0.94 \mathrm{mg} / \mathrm{ml})$ in $0.1 \mathrm{M}$ Tris $\cdot \mathrm{HCl}$ buffer (pH 8.0$)$ was titrated with $p$-mercuribenzoate at $26^{\circ} \mathrm{C}$ by addition of $5-\mu$ l aliquots of $p$-mercuribenzoate solution $(0.544 \mathrm{mM})$ in a stepwise manner. The sulfhydryl titer was determined spectrophotometrically at $250 \mathrm{~nm}$. After each addition, aliquots were removed and assayed for aldolase activity. (0), activity of the enzyme titrated with $\mathrm{Nbs}_{2} ;(\bullet)$, activity of the enzyme treated with $p$-mercuribenzoate; $X$, maximum reactivation of the enzyme obtained after incubation with $0.1 \mathrm{M}$ 2-mercaptoethanol.

$p$-mercuribenzoate-treated enzyme with excess 2-mercaptoethanol $(0.1 \mathrm{M})$ restores $80 \%$ of the initial enzymic activity; virtually complete reactivation of $\mathrm{Nbs}_{2}$-enzyme occurs under the same conditions (Fig. 3).

\section{Protection against $\mathrm{Nbs}_{2}$ inactivation by substrates}

2-Oxo-4-hydroxyglutarate aldolase activity is decreased 2-fold when the enzyme has four of its -SH groups (Classes I and II) titrated with $\mathrm{Nbs}_{2}$. With three -SH groups modified in the presence of pyruvate or glyoxylate (Table II), only $10 \%$ of the activity of the native enzyme is lost. This protection against $\mathrm{Nbs}_{2}$ inactivation by substrates can also be demonstrated when the aldolase is reacted with $0.5 \mathrm{mM} \mathrm{Nbs}{ }_{2}$ at $37^{\circ} \mathrm{C}$ (Table III). At this higher temperature, about $85 \%$ of the initial enzymic activity is destroyed within 90 min in the absence of substrates, whereas over the same interval of time only about $50 \%$ inactivation occurs in the presence of either $5 \mathrm{mM}$ pyruvate or $5 \mathrm{mM}$ glyoxylate. No further protection occurs in the presence of both substrates $(5 \mathrm{mM}$ each)*. Extended incubation $(3 \mathrm{~h})$ of the native enzyme with $\mathrm{Nbs}_{2}$ at $37^{\circ} \mathrm{C}$ results in only a small additional decrease $(3-5 \%)$ in activity.

* When 2-ox0-4-hydroxyglutarate aldolase is treated with $\mathrm{Nbs}_{2}(0.5 \mathrm{mM})$ at $37^{\circ} \mathrm{C}, 85 \%$ inactivation is associated with the titration of six - SH groups; the protective influence of pyruvate $(5 \mathrm{mM})$, glyoxylate ( $5 \mathrm{mM}$ ), pyruvate plus glyoxylate ( $5 \mathrm{mM}$ each), 2-oxo-4-hydroxyglutarate (5 mM), or even the competitive inhibitor, 2-oxoglutarate $(5 \mathrm{mM})$, against inactivation is accompanied by a decrease in one titratable - $\mathrm{SH}$ group. 


\section{TABLE III}

INACTIVATION OF 2-OXO-4-HYDROXYGLUTARATE ALDOLASE BY Nbs 2 IN THE PRESENCE OF SUBSTRATES

Reaction of the enzyme $(0.33 \mathrm{mg} / \mathrm{ml})$ with $\mathrm{Nbs}_{2}$ was carried out under the conditions specified in the legend of Fig. $1 \mathrm{~A}$, except that the temperature was $37^{\circ} \mathrm{C}$. Substrates were added as indicated. After a 90 min incubation, the solutions were assayed for aldolase activity after being dialyzed against $10 \mathrm{mM}$ Tris $\cdot \mathrm{HCl}$ buffer ( $\mathrm{pH} 7.4$ ) at $4^{\circ} \mathrm{C}$. 2-Oxoglutarate is a competitive inhibitor of aldolase activity.

\begin{tabular}{ll}
\hline Additions & Aldolase activity remaining \\
$(\%)$
\end{tabular}

\section{None}

\section{7}

$5 \mathrm{mM}$ pyruvate $\quad 51$

$5 \mathrm{mM}$ glyoxylate $\quad 54$

$5 \mathrm{mM}$ pyruvate $+5 \mathrm{mM}$ glyoxylate $\quad 50$

$5 \mathrm{mM}$ 2-oxo-4-hydroxyglutarate $\quad 55$

5 mM 2-oxoglutarate $\quad 51$

Effect of $\mathrm{Nbs}_{2}$ on the $\beta$-decarboxylase activity of 2-oxo-4-hydroxyglutarate aldolase

Results obtained previously [7] indicated that inactivation of 2-oxo-4hydroxyglutarate aldolase activity by tetranitromethane occurs with the concomitant loss of oxalacetate $\beta$-decarboxylase activity. These two catalytic activities of the enzyme are also affected equally by treatment of the aldolase with $\mathrm{Nbs}_{2}$ (Table IV). In addition, the protective effect of pyruvate on the rate of $\mathrm{Nbs}_{2}$ inactivation is the same for both aldolase and $\beta$-decarboxylase activities.

\section{Discussion}

8-10 sulfhydryl groups of bovine liver 2-oxo-4-hydroxyglutarate aldolase react with $\mathrm{Nbs}_{2}$ in the presence of sodium dodecyl sulfate or guanidine $\cdot \mathrm{HCl}$. All of these -SH residues can be titrated with $p$-mercuribenzoate in the absence of a denaturing agent, but the rate of interaction with $p$-mercuribenzoate does

\section{TABLE IV}

EFFECT OF Nbs, ON THE ALDOLASE AND $\beta$-DECARBOXYLASE ACTIVITIES OF 2-OXO-4HYDROXYGLUTARATE ALDOLASE

Aldolase $(0.33 \mathrm{mg} / \mathrm{ml})$ was incubated for $90 \mathrm{~min}$ at $37^{\circ} \mathrm{C}$ with $\mathrm{Nbs}_{2}$ or $\mathrm{Nbs}_{2}$ plus pyruvate, as indicated, in $50 \mathrm{mM}$ Tris $\mathrm{HCl}$ buffer ( $\mathrm{pH} \mathrm{8.0}$ ). Aliquots were withdrawn, diluted and assay ed for aldolase and $\beta$-decarboxylase activities.

\begin{tabular}{llr}
\hline Additions & $\begin{array}{l}\text { Aldolase activity } \\
\text { remaining } \\
(\%)\end{array}$ & $\begin{array}{l}\beta \text {-Decarboxylase activity remaining } \\
(\%)\end{array}$ \\
\hline None & 100 & 100 \\
$0.02 \mathrm{mM} \mathrm{Nbs}_{2}$ & 62 & 60 \\
$0.50 \mathrm{mM} \mathrm{Nbs}$ & 18 & 18 \\
$0.50 \mathrm{mM} \mathrm{Nbs}_{2}+5 \mathrm{mM}$ & 18 \\
pyruvate & 51 & 47 \\
\hline
\end{tabular}


not show any differences among the thiol groups in the enzyme. With $\mathrm{Nbs}_{2}$, however, three distinct types of sulfhydryls in 2-oxo-4-hydroxyglutarate aldolase can be differentiated. The first class consists of one - $\mathrm{SH}$ group which is highly reactive in the disulfide-exchange reaction. Class II is composed of three cysteinyl residues which titrate with $\mathrm{Nbs}_{2}$ at approx. 0.1 the rate of the single Class I -SH group. 4-6 additional thiols in the protein become available for reaction with $\mathrm{Nbs}_{2}$ only in the presence of a denaturant. This difference in titration behavior between $p$-mercuribenzoate and $\mathrm{Nbs}_{2}$ may be related to their molecular sizes; whereas the relatively small $p$-mercuribenzoate molecule apparently reacts readily with less accessible cysteinyl residues, the larger size of $\mathrm{Nbs}_{2}$ may hinder reaction with buried thiol groups.

Pyruvate and glyoxylate alter the reactivity of -SH groups in 2-oxo-4hydroxyglutarate aldolase. Both ligands abolish the reactivity of one thiol group in Class II towards $\mathrm{Nbs}_{2}$ and also substantially protect the enzyme against inactivation by this reagent. It is not likely that these protective effects are due to masking of this residue because of direct binding of substrate since a significant reduction in reactivity of the other three Class I and II -SH groups is also observed; steric hindrance considerations alone would not seem adequate to explain such results. Rather, these results suggest that 2-oxo-4-hydroxyglutarate aldolase exists in an altered conformational state in the presence of its cosubstrates. The possibility of ligand-induced conformational changes is further strengthened by the protective influence provided by substrates against denaturation of 2-oxo-4-hydroxyglutarate aldolase by $8 \mathrm{M}$ urea. Moreover, although previous binding studies have shown that $1 \mathrm{~mol}$ of pyruvate or glyoxylate is bound per mol of enzyme in azomethine linkage [3-5] up to two thiols in the native enzyme are protected from reaction with $p$-mercuribenzoate. Of particular interest is the observation that both ligands elicit parallel effects on the reactivity of thiol residues towards $\mathrm{Nbs}_{2}$ or $p$-mercuribenzoate as well as in protecting the aldolase from urea denaturation and $\mathrm{Nbs}_{2}$ inactivation. Thus, a similar conformational change may result from the binding of pyruvate and glyoxylate at a common site on the protein molecule. Competitive binding studies performed previously indicate that both ligands more than likely undergo imine formation with the same active-site lysyl residue [3-5]. Experiments are in progress to further define the nature and the magnitude of the structural changes observed by -SH titration.

Although 2-oxo-4-hydroxyglutarate aldolase is extensively inactivated by reaction with $\mathrm{Nbs}_{2}$ or $p$-mercuribenzoate, and substrate protection against inactivation is associated with a decrease in 1-2 titratable thiol groups, it is apparent that these -SH residues cannot play a major role in substrate binding or catalysis since residual enzymic activity is consistently observed following complete titration of the enzyme with either reagent. We conclude, therefore, that the thiol groups of 2-oxo-4-hydroxyglutarate aldolase are essential in maintaining the active conformation of the enzyme required for maximum expression of both aldolase and $\beta$-decarboxylase activities (Table IV), and interpret the results with $\mathrm{Nbs}_{2}$ and $p$-mercuribenzoate as being due to a progressive and general loss of this conformation which accompanies titration of sulfhydryl groups. A concomitant loss of aldolase and $\beta$-decarboxylase activities also occurs upon chemical modification of the enzyme with tetranitromethane [7]. 
In this instance, however, oxidation of four $-\mathrm{SH}$ groups results in complete inactivation of the enzyme. The difference between the effects of tetranitromethane and the reagents used in these studies are apparently related to the nature of the product formed and/or the change in protein structure accompanying modification. Inactivation of the aldolase by $\mathrm{Nbs}_{2}$ or $p$-mercuribenzoate is almost completely reversible by the addition of excess 2-mercaptoethanol (Fig. 3) while thiols are ineffective in reactivating the tetranitromethane-derivatized enzyme. Oxidation of - $\mathrm{SH}$ groups in 2-oxo-4-hydroxyglutarate aldolase by tetranitromethane produces cysteic acid and other unidentified products [7].

\section{Acknowledgments}

This investigation was supported in part by a research grant (AM-03718) from the National Institute of Arthritis, Metabolism, and Digestive Diseases, U.S. Public Health Service. B.A. Hansen was a predoctoral trainee of the U.S. Public Health Service, Grant GM-00187.

\section{References}

1 Kobes, R.D. and Dekker, E.E. (1967) Biochem. Biophys. Res. Commun, 27, 607-612

2 Kobes, R.D. and Dekkex, E.E. (1971) Biochim. Biophys. Acta 250, 238-250

3 Kobes, R.D. and Dekker, E.E. (1966) Biochem. Biophys. Res. Commun. 25, 329-334

4 Kobes, R.D. and Dekker, E.E. (1971) Biochemistry 10.388-395

5 Hansen, B.A., Lane, R.S. and Dekker, E.E. (1974) J. Biol. Chem. 249, 4891-4896

6 Kobes, R.D. and Dekker, E.E. (1969) J. Biol. Chem. 244, 1919-1925

7 Lane, R.S. and Dekker, E.E. (1972) Biochemistry 11, 3295-3303

8 Maitra, U. and Dekker, E.E. (1963) J. Biol. Chem. 238, 3660-3669

9 Boyer, P.D. (1954) J. Am. Chem. Soc. 76, 4331 -4337

10 Lowry, O.H., Rosebrough, N.J., Farr, A.L. and Randall, R.J. (1951) J. Biol. Chem. 193, 265-275

11 Gornall, A.G., Barda will, C.J. and David, M.M. (1949) J. Biol. Chem. 177, 751-766

12 Maitra, U. and Dekker, E.E. (1964) J. Biol. Chem. 239, 1485-1491

13 Ellman, G.L. (1959) Arch. Biochem. Biophys. 82, 70-77

14 Frost, A.A. and Pearson, R.G. (1961) Kinetics and Mechanism, 2nd edn., pp. 162-164, John Wiley and Sons, Inc., New York

15 Benesch, R. and Benesch, R.E. (1962) Methods Biochem. Anal. 10, 43-70 